\title{
From early to late neurogenesis: Neural progenitors and the glial niche from a fly's point of view
}

\author{
Pol Ramon-Cañellas ${ }^{\mathrm{a}}$, Hannah Payette Peterson ${ }^{\mathrm{a}}$ and Javier Morante ${ }^{\mathrm{a}, \mathrm{b}}$ \\ anstituto de Neurociencias, Consejo Superior de Investigaciones Científicas (CSIC); and Universidad Miguel \\ Hernandez (UMH), Campus de Sant Joan, Apartado 18, 03550 Sant Joan, Alicante, Spain.

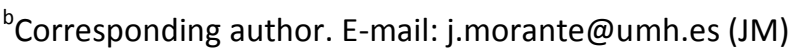

NUMBER OF PAGES: 30 (including references, figure legends etc.)

NUMBER OF FIGURES: 4

NUMBER OF WORDS ABSTRACT: 247

NUMBER OF WORDS INTRODUCTION: 712

The authors declare no competing financial interests.

\section{Acknowledgements}

We apologize to those whose work we did not cite due to focus and space limitations. We thank Stuart B. Ingham for helping with illustrations. This work was supported by the Ramon y Cajal Program (RyC-2010-07155), a Spanish National Grant (BFU2016-76295-R) co-financed by the European Regional Development Fund (ERDF), and the Severo Ochoa Program for Centres of Excellence in R\&D (SEV-2017-0723) to Javier Morante. Pol Ramon-Cañellas is a FPI fellow (BES-2013064947) from the Spanish Ministerio de Economia y Competitividad. 


\section{Abstract}

Drosophila melanogaster is an important model organism used to study the brain development of organisms ranging from insects to mammals. The central nervous system in fruit flies is formed primarily in two waves of neurogenesis, one of which occurs in the embryo and one of which occurs during larval stages. In order to understand neurogenesis, it is important to research the behaviour of progenitor cells that give rise to the neural networks which make up the adult nervous system. This behaviour has been shown to be influenced by different factors including interactions with other cells within the progenitor niche, or local tissue microenvironment. Glial cells form a crucial part of this niche and play an active role in the development of the brain. Although in the early years of neuroscience it was believed that glia were simply scaffolding for neurons and passive components of the nervous system, their importance is nowadays recognized. Recent discoveries in progenitors and niche cells have led to new understandings of how the developing brain shapes its diverse regions. In this review, we attempt to summarize the distinct neural progenitors and glia in the Drosophila melanogaster central nervous system, from embryo to late larval stages, and make note of homologous features in mammals. We also outline the recent advances in this field in order to define the impact that glial cells have on progenitor cell niches, and we finally emphasize the importance of communication between glia and progenitor cells for proper brain formation.

KEYWORDS: Drosophila, Central nervous system, Development, Neural progenitors, Glia, Niche.

ABBREVIATIONS: CNS: central nervous system; VZ: ventricular zone; SVZ: subventricular zone; NSCs: neural stem cells; NBs: neuroblasts; NECs: neuroepithelial cells; INPs: intermediate neural progenitors; GMCs: ganglion mother cells; TFs: transcription factors; VNC: ventral nerve cord; CB: central brain; OL: optic lobe. 


\section{Introduction}

Proper development of an organism's brain is crucial for successful communication between its organs and maintenance of their vital functions (Droujinine and Perrimon, 2016). Drosophila melanogaster has been instrumental in uncovering the molecular and cellular basis of fundamental developmental processes in metazoans, with research aided by an extensive range of genetic tools and reagents (Bellen et al., 2010). The fruit fly's transcriptome reveals that co-expression modules which are rich in developmental genes are shared across species (Gerstein et al., 2014), making it suitable for studying many biological principles also relevant for vertebrates (Ugur et al., 2016). Nowadays, studies of neurogenesis are carried out in Drosophila from the early embryo until the late larval stage.

Neurogenesis in Drosophila melanogaster takes place in two waves. The embryonic phase, when the first wave of neurogenesis takes place, has been the model system where historically the majority of in-depth studies of cell fate specification (e.g., NB5-6 generation of Apterous neurons; Baumgardt et al., 2007; Bivik et al., 2015) and neuronal wiring (e.g., generation of RP1, 2, 3, 4, 5 and their innervation of specific single muscle fibres; Landgraf and Thor, 2006) have been carried out at singlelineage and single-cell resolution. Although it is during embryogenesis that researchers have most effectively studied the development of neural circuits and their versatility, recent research on larval development, when the second wave of neurogenesis takes place, has allowed scientists to gather novel insights into generic lineages that give rise to specialised cell populations (Baek and Mann, 2009; Clark et al., 2016; Couton et al., 2015; Heckscher et al., 2015; Kim et al., 2009).

Neural progenitors are multipotent, and thus can proliferate and differentiate into varied cell types in response to both intrinsic and extrinsic cues (Doe, 2017; Knoblich, 2008; Kohwi and Doe, 2013; Morante et al., 2013; Speder et al., 2011; Syed et al., 2017a). Though more is currently known about intrinsic than extrinsic cues (Paridaen and Huttner, 2014; Tiberi et al., 2012), an understanding of both is extremely important for describing the modulation of brain development within different 
stem cell niches. Niches are local tissue microenvironments that maintain and regulate stem cell their development and behaviour (Lehtinen and Walsh, 2011; Lehtinen et al., 2011; Morrison and Spradling, 2008; Siegenthaler et al., 2009; Siegenthaler and Pleasure, 2011). It is clear that extrinsic cues received by stem cells need to be effectively interpreted to produce the correct intrinsic responses, but little is known about the specifics of these interactions.

In the nervous system, glial cells, like neurons, comprise a significant portion of the brain. However, in the early ages of brain science, glia were thought to serve only as scaffolding for neurons and to play a passive role in the nervous system. Nowadays, in contrast to what was initially believed, it is accepted that glia also play a relevant part in brain formation, and are important not only in structural development but also in controlling stem cell division (Awasaki et al., 2008; DeSalvo et al., 2014; Kanai et al., 2018; Kriegstein and Alvarez-Buylla, 2009; Okamoto and Nishimura, 2015; Ou et al., 2016). However, more knowledge of their interaction with precursor stem cells is needed. Since glia are so vital for brain growth and function, they have been thoroughly studied in organisms from Drosophila to vertebrates (Freeman, 2015; Freeman and Doherty, 2006; Hartenstein, 2011; Ou et al., 2014; Zuchero and Barres, 2015). In this review, we cover the interesting insights that the Drosophila central nervous system (CNS) has provided via studies carried out in stem cell niches (Banerjee et al., 2017; Berger et al., 2012) with vanguard systems of elementary genetic manipulation (Gratz et al., 2013; Manning and Doe, 2017; Sarov et al., 2016), and we attempt to contextualize the significance of these discoveries in the framework of vertebrates. To do so, we first provide an overview of the elements that constitute the stem cell niche, from embryonic (Figure 1) to larval (Figure 2 and Figure 3) progenitors and glia (Figure 4), and then explain their roles in the microenvironment they share. Finally, we end with the role that the glial niche may play in brain injuries and disease and emphasize the importance of future research on CNS development.

\section{Drosophila neural stem cells}


Drosophila neural stem cells (NSCs), known as neuroblasts (NBs), are a useful model for studying the complexity of brain development from youth to adulthood (Clark et al., 2018; Enriquez et al., 2018; Ito et al., 2013; Jefferis et al., 2001; Marin et al., 2002; Sato et al., 2013; Yang et al., 2013; Yu et al., 2013; Figure 1 and Figure 2). Thus, the widely-understood temporal transition in the NBs of the fly brain (Baumgardt et al., 2009; Bayraktar and Doe, 2013; Brody and Odenwald, 2000; Doe, 2017; Grosskortenhaus et al., 2005; Holguera and Desplan, 2018; Kambadur et al., 1998; Li et al., 2013; Maurange, 2012; Sato et al., 2013; Suzuki et al., 2013) has given insight into how similar sequential gene expression occurs in mammalian corticogenesis (Delaunay et al., 2017; Holguera and Desplan, 2018), for instance in the independent cell-cycle progression (Okamoto et al., 2016) or to confer early temporal competence to retinal progenitor cells (Elliott et al., 2008).

NBs undergo distinct modes of cell division to shape different areas of the brain (Figure 1 and Figure 3). The behaviour of progenitors depends on three parameters: first, each cell's identity; second, each cell's intrinsic timer status; and finally, each cell's location, or immediate environment. Regarding the first parameter, for example, the nature of two classical types of fly NBs (type I and type II) has been broadly studied (Doe, 2017). These two subtypes mainly differ on whether or not neurogenesis is mediated by the intermediate neural progenitors (INPs) prior to the production of ganglion mother cells (GMCs; Bello et al., 2008; Boone and Doe, 2008; Bowman et al., 2008; Figure $1 \mathrm{~A}-2$ and Figure $3 \mathrm{~A})$. In contrast, type 0 NBs produce progeny that directly differentiate into neurons (Ulvklo et al., 2012; Figure 1C-2 and Figure 3B). The second parameter consists of the sequential expression of transcription factors (TFs) in progenitors, a phenomenon known as temporal patterning (Baumgardt et al., 2009; Brody and Odenwald, 2000; Doe, 2017; Grosskortenhaus et al., 2005; Kambadur et al., 1998; Li et al., 2013; Maurange, 2012; Sato et al., 2013; Suzuki et al., 2013), which is important for the generation of the neural diversity required in adults. The final parameter that influences progenitor behaviour is the place, or environment, in which each progenitor resides, as each progenitor is exposed to a varying set of extrinsic cues depending on its location (Ferraro et al., 2010; Morrison and Spradling, 2008). The effect of each NB's environment is evidenced by the fact 
that the same NB types may give rise to different neuronal populations depending on where they are

located. For example, type $0 \mathrm{NBs}$ have been described in late-embryonic ventral nerve cord (Baumgardt et al., 2014; Figure 1C-1) and larval optic lobe NB lineages (Bertet et al., 2014; Figure 2B2). Some of the extrinsic cues involved in regulating cell division have been identified, as we will explain later. To make clear the progenitor types and their environments, we have divided them into the three main regions of the Drosophila CNS depending their origin: NBs of the central brain (CB; Figure $1 \mathrm{~A}$ and Figure $2 \mathrm{~A}$ ), which delaminate from the embryonic procephalic neuroectoderm; NBs of the optic lobes (OLs; Figure 1B and Figure 2B), which delaminate from the neuroectoderm during embryogenesis and arise postembryonically via transformation from the $\mathrm{OL}$ proliferative neuroepithelium derived from an embryonic optic placode; and NBs of the ventral nerve cord (VNC; Figure $1 \mathrm{C}$ and Figure $2 \mathrm{C}$ ), which delaminate from the embryonic VNC neuroectoderm.

\section{Embryonic progenitors}

Systematic studies of Drosophila embryonic NBs with single-lineage and single-cell resolution have elucidated the mechanisms controlling the generation of cellular diversity in the developing CNS, providing a detailed map of molecular markers of NBs in the early embryonic brain (Bossing et al., 1996; Doe, 2017; Schmidt et al., 1997; Urbach and Technau, 2004). Knowledge of the embryo also allows for the tracking of development from embryonic to larval stages and thus better contextualizes discoveries made in larvae. In this review, the terms VNC, CB and OL are used to refer to the parts of the embryonic CNS in order to maintain consistency with the terminology used in other stages of development.

The Drosophila VNC (Figure 1C), which is analogous to the spinal cord in vertebrates, is a region of the insect CNS in which temporal patterning of NBs was first observed (Baumgardt et al., 2009; Brody and Odenwald, 2000; Doe, 2017; Grosskortenhaus et al., 2005; Kambadur et al., 1998). In the VNC there are 30 NBs per bilateral hemisegment, arranged in rows and columns, which leads to their row/column naming scheme (e.g., NB5-6 is in row 5, column 6; Broadus et al., 1995; Hartenstein et 
al., 1994; Figure 1C-1). Most, if not all, VNC NBs begin in type I mode: they undergo several rounds of Notch-dependent asymmetric cell division to produce a self-renewed NB and a series of smaller GMCs that typically differentiate into a pair of neurons (Buescher et al., 1998; Figure 1C-2). Subsequently, many of these type I NBs switch to type 0 mode, and each type 0 NB divides asymmetrically to self-renew and produce one neuron (Baumgardt et al., 2014; Baumgardt et al., 2009; Monedero Cobeta et al., 2017; Ulvklo et al., 2012; Figure 1C-2). This switch is controlled by a temporal cascade, a series of five TFs (Hunchback (Hb), Krüppel (Kr), Pdm1/Pdm2 (Pdm), Castor (Cas) and Grainy head (Grh)) that are expressed sequentially during lineage development. $\mathrm{Hb}, \mathrm{Kr}$ and $\mathrm{Pdm}$ promote type I proliferation and Cas and Grh promote type 0 proliferation and NB cell cycle exit (Bahrampour et al., 2017). The orphan nuclear receptor Seven-up (Svp) and the Pipsqueak domain proteins Dan and Danr promote the $\mathrm{Hb}$ to $\mathrm{Kr}$ switch by working synergistically to repress $\mathrm{Hb}$ transcription (Kanai et al., 2005; Kohwi et al., 2011; Mettler et al., 2006). Temporal factors control the competence of the NB, as demonstrated by the generation of different types of neurons and glia at different time points (Baumgardt et al., 2009; Grosskortenhaus et al., 2005; Isshiki et al., 2001; Moris-Sanz et al., 2014).

As in many species, the Drosophila brain undergoes even greater expansion than the VNC throughout development (Yaghmaeian Salmani et al., 2018). Like in the VNC, type I NBs are present in the embryonic CB (Figure 1A-1), around 100 per hemisphere (Urbach et al., 2003; Urbach and Technau, 2004), although they do not switch to type 0 (Figure 1A-2). Recently, type II NBs have also been found to be present (Alvarez and Diaz-Benjumea, 2018; Walsh and Doe, 2017; Figure 1A-1 and Figure 1A-2). Mushroom body (MB) NBs are also found in the embryonic $C B$ (Figure 1A-1), and divide in a mode similar to that of type I NBs, producing neurons via GMCs (Figure 1A-2); they eventually produce the Kenyon cells of the adult MB. Hence, there is a gradient of proliferation in the embryonic brain: there are a dozen hyperproliferative NBs (four MB NBs and eight type II NBs per brain lobe) while the rest of the brain's NBs exhibit exclusively type I behaviour (Alvarez and DiazBenjumea, 2018; Walsh and Doe, 2017; Yaghmaeian Salmani et al., 2018). 
Although it was previously thought that OL development did not begin until larval stages, it was very

recently discovered that in late embryogenesis, neuroepithelial cells (NECs) in the embryonic region that later gives rise to the $\mathrm{OL}$ delaminate into canonical NBs called embryonic optic neuroblasts (EONs; Hakes et al., 2018; Figure 1B-1). These EONs generate neurons and glia (Figure 1B-2).

At the end of embryogenesis, most of the remaining embryonic NBs in the entire CNS, except MB NBs (Kunz et al., 2012), enter into a quiescent state or are eliminated by apoptosis (Hakes et al., 2018; Truman and Bate, 1988; White et al., 1994). It is during the larval stage when they exit quiescence in a nutrition-dependent manner to start the second wave of neurogenesis (Chell and Brand, 2010; Lanet et al., 2013; Sousa-Nunes et al., 2011; Speder et al., 2011), generating the more complex CNS required for adult life.

\section{$\underline{\text { Larval central brain and ventral nerve cord neuroblasts }}$}

Unlike in the embryo, the VNC in larval stages consists of only type I NBs (Figure 2C and Figure $3 \mathrm{C}$ ) while the larval CB has type I, type II, MB and antennal lobe (AL) NBs (Das et al., 2013; Doe, 2017; Homem and Knoblich, 2012; Sousa-Nunes et al., 2010; Figure 2A and Figure 3A). In larvae, type I NB cells, which are reactivated following the embryonic stage, are Deadpan (Dpn) $)^{+}$Asense $(A s e)^{+}$Pointed 1 (PntP1; Pnt)- and produce GMCs that are Dpn ${ }^{-}$Prospero (Pros) ${ }^{+}$(Xie et al., 2016; Zhu et al., 2011). Unlike in the embryo, postembryonic type I NBs do not use $\mathrm{Hb}, \mathrm{Kr}$ and $\mathrm{Pdm}$ to regulate temporal specification. In early larval stages, these NBs express Cas and give rise to a series of early-born neurons expressing the BTB transcription factor Chronologically inappropriate morphogenesis (Chinmo) and later-born neurons expressing Broad (Br; Maurange et al., 2008; Zhu et al., 2006). Svp is re-expressed in larval NBs to trigger this temporal transition from Chinmo to $\mathrm{Br}$ expression by terminating Cas expression (Maurange et al., 2008).

As in the embryo, there are eight type II NBs per brain lobe (Figure 2A): six dorsal medial (DM1-6) and two dorsal lateral (DL1 and DL2). Type II NBs have a distinct molecular profile, which is $\mathrm{Dpn}^{+} \mathrm{Ase}^{-}$ 
$\mathrm{PntP1}^{+}$(Doe, 2017; Homem and Knoblich, 2012; Sousa-Nunes et al., 2010). These NBs also temporally express a series of factors including Dichaete (D), Cas and Svp (Bayraktar and Doe, 2013). As with neural progenitors in the human outer subventricular zone (SVZ; (Doe, 2017; Fernandez et al., 2016; Homem and Knoblich, 2012), type II NBs asymmetrically divide to generate INPs with the molecular profile $\mathrm{Dpn}^{+} \mathrm{Ase}^{+}$. These INPs also sequentially express the TFs D, Grh and Eyeless (Ey) in order to each generate approximately six GMCs that are $\mathrm{Dpn}^{-} \mathrm{Ase}^{+}$, which then differentiate into distinct neural cell types (Bayraktar and Doe, 2013; Bello et al., 2008; Boone and Doe, 2008; Bowman et al., 2008; Izergina et al., 2009; Zhu et al., 2011; Figure 3A). Together, these expression patterns in NBs and INPs increase the neural diversity in the adult fruit fly CNS. The aforementioned factors, along with novel candidate temporal factors expressed by larval NBs (Ren et al., 2017; Syed et al., 2017b) including the Ecdysone receptor (Syed et al., 2017b), were identified via the use of unbiased transcriptomic approaches. Further analysis will reveal the role of those potential novel temporal factors.

Also located in the larval $C B$ are four MB NBs per hemisphere (Figure $2 A$ ), which emerge during the embryonic period and continuously divide during development until early adult stages without entering into quiescence (Kunz et al., 2012; Lee et al., 1999). Each give rise to three neuronal lineages, which together generate the adult centres for olfactory associative learning and cognitive functions (Lee et al., 1999). The cell division mode of MBs is similar to that of type I NBs: they produce MB neurons via GMCs (Figure 3A). Based on the age of the larva, two RNA-binding proteins, IGF-II mRNA-binding protein (Imp) and Syncrip (Syp), display opposing temporal gradients: young NBs have high Imp and low Syp expression, middle-aged NBs express both, and old NBs have low Imp and high Syp expression (Liu et al., 2015). The expression of these proteins thus controls mushroom body lineages by regulating translation of the temporal transcription factor Chinmo (Liu et al., 2015; Narbonne-Reveau et al., 2016). 
The ALs are an important part of the olfactory system in Drosophila. The functioning olfactory system

in larvae is generated in the embryo (Marin et al., 2005; Yu et al., 2010), although knowledge of which specific embryonic progenitor cells give rise to the olfactory system is limited. In larvae, the system consists of 21 olfactory sensory neurons located in the antenno-maxillary complex which then form 21 subunits called glomeruli consisting of 21 projections and 21 local interneurons (Ramaekers et al., 2005). In each of the two larval ALs there are five NBs (Figure 2A), which are defined as anterodorsal (adNB/BAmv3), lateral (INB/BAlc), ventral (vNB/BAla1), ventrolateral (vINB/BAla2) and BAlp4 (Das et al., 2013). These AL NBs found in larvae give rise to the adult olfactory system, which is much more complex. Larval AL NBs undergo proliferation and can generate approximately 40 neuron types from a single hemilineage (Yu et al., 2010). GMCs descended from these larval AL NBs (Figure 3A) make daughter cells with distinct neuronal A/B fates due to a Notchmediated binary sister fate decision. Notably, many CNS lineages exist as a lone hemilineage because one entire hemilineage may undergo premature cell death as a result of this binary decision (Lin et al., 2012; Lin et al., 2010; Yu et al., 2010). Using this neurogenic strategy, during larval stages AL NBs generate approximately 200 adult olfactory projection neurons and 100 local interneurons (Das et al., 2013; Das et al., 2008; Jefferis et al., 2001; Lai et al., 2008; Yu et al., 2013). AL NBs end proliferation around pupation. Within each adult AL, approximately 1300 olfactory receptor neurons expressing the same receptors make connections to two types of interneurons, projection neurons and local interneurons, forming approximately 50 glomeruli (Vosshall et al., 2000). Projection neurons extend their axons to higher brain centres in the MB and lateral horn (Jefferis et al., 2001). The behaviour of developmental progenitors in the OL is more complex, and will be discussed next.

\section{Larval optic lobe progenitors}

The $\mathrm{OL}$ is the largest part of the Drosophila brain; it has four ganglia and is dedicated solely to vision, which reveals the importance of this sense for adult flies (Morante and Desplan, 2004). Neurons of 
the mature OL are produced during the larval and early pupal periods (Hofbauer and Campos-Ortega, 1990).

Larval NECs delaminate into $800 \mathrm{OL} \mathrm{NBs,} \mathrm{which} \mathrm{asymmetrically} \mathrm{divide} \mathrm{to} \mathrm{self-renew} \mathrm{and} \mathrm{start}$ neurogenesis and gliogenesis (Figure 2B and Figure 3B; Egger et al., 2007; Yasugi et al., 2008). This process resembles the behaviour of progenitors in the mammalian forebrain, which first divide symmetrically and then later divide asymmetrically to produce NSCs (Brand and Livesey, 2011; Gotz and Huttner, 2005; Kriegstein and Alvarez-Buylla, 2009). This region was thought to be unlike the rest of the fruit fly CNS, with most of the OL NBs transforming from NECs beginning at the second-instar larval stage (Ceron et al., 2001; Egger et al., 2007). However, as previously discussed in the section "Embryonic progenitors", a recent study has challenged this view (Hakes et al., 2018), showing that embryonic OL NECs start to produce EONs during embryonic development (Figure 1B).

Characterization by molecular markers and morphology indicates that the four fly OL ganglia originate from two distinct neuroepithelial regions (Figure 2): the outer proliferation centre (OPC; Figure $2 \mathrm{~B}-1$ and Figure $2 \mathrm{~B}-2$ ), which gives rise to the medulla and lamina neuropils, and the inner proliferation centre (IPC; Figure 2B-3), which produces the lobula and lobula plate neurons (Apitz and Salecker, 2015; Hasegawa et al., 2011; Hofbauer and Campos-Ortega, 1990; Li et al., 2013; Meinertzhagen and Hanson, 1993; Mora et al., 2018; Morante and Desplan, 2004, 2011; Morante et al., 2011; Pinto-Teixeira et al., 2018). Although they originate in different parts of the brain, these neuron types have been found to interact with one another in order to establish the various neuropil compartments (Suzuki et al., 2016).

The OPC neuroepithelium (Figure 2B-1 and Figure 2B-2) is patterned into spatial domains along the anterior-posterior axis by expression of Visual system homeobox 1 (Vsx1), Optix, Decapentaplegic (Dpp) and Wingless (Wg; Erclik et al., 2008; Erclik et al., 2017; Gold and Brand, 2014). This region can also be subdivided morphologically into the medial domain (m-OPC) and the lateral domain (I-OPC), which are separated by the lamina furrow (LF; Figure 2B-1). Differentiation of NBs from NECs in the 
m-OPC and I-OPC is controlled at first by Notch, which maintains NECs, and then by JAK/STAT, which negatively regulates proneural wave progression; both Notch and JAK/STAT thus impede the switch from symmetric to asymmetric cell division (Egger et al., 2010; Ngo et al., 2010; Reddy et al., 2010; Yasugi et al., 2010; Yasugi et al., 2008). Later in development, Notch signalling remains active only in the m-OPC, which eventually gives rise to medulla neurons, while JAK/STAT signalling remains active only in the I-OPC, which gives rise to lamina neurons (Ngo et al., 2010). Apart from the ganglia they generate, these regions also differ in their distinct forms of neurogenesis, which we will discuss next. In larval development in the m-OPC, dietary nutrients trigger insulin/PI3K/TOR signalling to regulate NEC proliferation (Lanet et al., 2013). The Fat-Hippo pathway also plays a role in regulation of growth through proliferation of NECs, and later arrests these cells in the G1 phase of the cell cycle before their conversion to NBs (Reddy et al., 2010). In late larval stages, proliferation becomes insensitive to dietary nutrients and the steroid hormone Ecdysone becomes active. Ecdysone acts via Delta/Notch signalling to initiate the shift from symmetric/proliferative cell division to asymmetric/neurogenerative cell division (Lanet et al., 2013). Expression of the proneural protein Lethal-of-scute (L(1)sc), which is induced by epidermal growth factor (EGF) receptor signalling, also promotes the conversion of NECs to NBs (Egger et al., 2010; Morante et al., 2013; Yasugi et al., 2010; Yasugi et al., 2008; Figure 2B-1). The microRNA miR-7, along with other factors, is important for buffering this transition (Caygill and Brand, 2017). In type I NBs, temporal expression of six different TFs (Homothorax (Hth), Klumpfuss (Klu), Ey, Sloppy-paired (Slp), D and Tailless (TII)) acts in tandem with Notch-dependent binary fate choice to control differentiation of the neuronal progeny (Doe, 2017; Li et al., 2013; Suzuki et al., 2013; Figure 3B). Overall, the integration of this temporal signalling with spatial cues is essential for generating neural diversity (Erclik et al., 2017).

In the m-OPC, there is a particular area located in the tip of the OPC (tip-OPC; Figure 2B-2) in which NB behaviour depends on two temporal windows. First, when the TF Distalless (DII) is expressed, NBs divide in type 0 mode; type 0 NBs were originally described in the embryo and are the only 
postembryonic NBs which give rise to neuron progeny directly without further cell divisions (Bertet switch to type I division mode, though half of their progeny is eliminated via apoptosis. This temporal expression of TFs contributes to the generation of diverse neural subtypes in the tip-OPC that innervate the medulla, lobula and lobula plate in adult flies (Bertet et al., 2014); Figure 3B).

Another type of progenitor, common progenitor cells (CPCs), delaminate from NECs of the tip-OPC (Chen et al., 2016; Figure 2B-2). CPCs do not express the canonical NB marker Dpn but do express Pros and Ase, and therefore more closely resemble GMCs. CPCs divide asymmetrically to generate two distinct precursor cell populations: lamina wide-field precursor cells (Lawf PCs) and glial precursor cells (GPCs; Figure 2B-2 and Figure 3B). Each one of the latter two precursor types divide symmetrically and respectively generate Lawf neurons and lamina glia (Chen et al., 2016; Fischbach and Dittrich, 1989; Hasegawa et al., 2011; Winberg et al., 1992; Figure 3B). This neurogliogenesis fate choice mediated by the Notch pathway resembles in many ways the role that Notch signalling plays in vertebrates in establishing neurogenic or gliogenic phases during development (Gaiano and Fishell, 2002; Rowitch and Kriegstein, 2010; Taylor et al., 2007). Finally, after the precursor cells differentiate into glia and Lawf neurons, both these cell types migrate to their position in the medulla (Chen et al., 2016).

NECs in the I-OPC (Figure 2B-1) generate non-NB cells in the G2-phase, which divide symmetrically to produce lamina neurons (Figure 3B). These posterior LF progenitors, called lamina precursor cells (LPC; Figure 2B-1), proliferate and differentiate in a manner regulated by sequential release of secreted factors by photoreceptors (PRs). First, PRs release Hedgehog to promote terminal divisions of NECs, and second they release Spitz/TGF- $\alpha$ and Fibroblast growth factor (FGF) which respectively activate EGF receptor and FGF receptor in relay wrapping glia (Fernandes et al., 2017; Franzdottir et al., 2009; Huang and Kunes, 1996, 1998; Huang et al., 1998; Selleck and Steller, 1991). While EGF receptor activation is required for lamina neuron differentiation via insulin signalling (Fernandes et 
al., 2017), FGF receptor signalling is required to induce glial cell differentiation such that glia wrap

The other proliferation centre, the IPC (Figure 2), consists of three domains, which are defined based on their location as surface, proximal and distal IPC (s-IPC, p-IPC and d-IPC, respectively; Apitz and Salecker, 2015). At the same time, the cells of the IPC belong to two proliferative zones: in the p-IPC region NECs divide symmetrically while the d-IPC is composed of NBs derived from the $p$-IPC cells (Figure 2B-3). Specifically, NECs in the p-IPC express either Dpp or Brinker (Brk), a negative regulator of Dpp target genes, which determines whether the NECs will give rise to either vertical or horizontal motion selective neurons (Apitz and Salecker, 2015, 2018; Mora et al., 2018; Pinto-Teixeira et al., 2018).

The IPC NECs then delaminate into migrating progenitors (MPs), which move from the p-IPC to the $d$ IPC (Apitz and Salecker, 2015; Figure 2B-3 and Figure 3B). This mechanism, which resembles the epithelial-mesenchymal transition, is required for facilitating spatio-temporal matching of neurogenesis and neuronal connectivity, and is similar to the migration of neurogenic radial glia-like cells from the meninges to the neonatal cortex of mice that then differentiate into functional integrated neurons (Bifari et al., 2017). Once MPs reach the d-IPC, they differentiate into NBs (Figure 2B-3 and Figure 3B) that sequentially express $D$ and Ase and then TIl, Ato and Dac. These NBs first go through type I cell division orchestrated by Ase TFs to produce C- and T-neurons (Apitz and Salecker, 2015). When the NBs enter to the Ato temporal window they exclusively produce T4 and T5 neurons which respectively detect bright edge and dark edge motion (Apitz and Salecker, 2015; Oliva et al., 2014). Two alternative and likely coexisting models have been proposed for the production of T neurons in the second competence window. In the first model, Ato $^{+}$NBs generated by either a horizontal or vertical progenitor undergo two sequential Notch-dependent divisions to produce matching sets of two T4 and two T5 neurons (Apitz and Salecker, 2018; Pinto-Teixeira et al., 2018). In the second model, a transient amplification of d-IPC NBs by symmetric cell division ensures that the 
correct number of T4 and T5 neurons is produced (Mora et al., 2018); the temporal transition in amplification. Although symmetric cell division in NBs has been previously described in mammals (Obernier et al., 2018), this is the first time it has been seen in Drosophila. Thus, these symmetrically dividing cells are categorised as type III NBs due to their initial self-propagation and subsequent loss of multipotency (Mora et al., 2018; Figure 2B-3 and Figure 3B).

\section{Glial cells in the Drosophila CNS}

Glial cells in Drosophila are genetically similar to glia in mammals, and express many TF homologs such as the gene glial cells missing $(\mathrm{gcm})$ which is responsible for glial cell fate (Freeman et al., 2003; Freeman and Doherty, 2006; Hosoya et al., 1995; Jones et al., 1995; Van De Bor and Giangrande, 2002). In the fruit fly, glial cells are derived from a small set of uniquely identifiable precursors (Figure 3). Glioblasts and neuroglioblasts, which are respectively named according to whether they give rise to only glia or both neurons and glia, delaminate from the neuroectoderm of the postgastrulation embryo (Beckervordersandforth et al., 2008; Stork et al., 2012; von Hilchen et al., 2008). These cells increase in number at the third instar larval stage due to two mechanisms: division of differentiated glial cells (Colonques et al., 2007) and continued division of neuroglioblasts (Larsen et al., 2009; Omoto et al., 2015; Ren et al., 2017; Viktorin et al., 2013). Finally, the glial diversity in the adult CNS depends on embryonic and larval temporal patterning, and it is thus crucial to study glial development in order to fully understand the structure of the adult brain (Awasaki et al., 2008).

The embryonic Drosophila VNC contains around 25-30 glia per hemisegment. These glia can be divided into three main categories according to their location and morphology. The first category is surface glia (SG), made up of perineurial glia (PG) and subperineurial glia (SPG), which surround the CNS and peripheral nerves and contribute to the formation of the blood-brain barrier (BBB). The second category is cortex glia (CG), which ensheath neuronal cell bodies. The third category is neuropil glia (NG), which associate directly with the neuropil (Hartenstein et al., 1998; Ito et al., 
1995; Pereanu et al., 2005). Apart from these three categories, midline glia are a small set of glia also present in the embryonic CNS; they play an important role in axon pathfinding at the CNS midline and commissure formation in the VNC (Jacobs, 2000). Midline glia later differentiate as ensheathing glia (Jacobs, 2000).

Though in past years there has been a significant effort to characterise glial cells in the larval Drosophila CNS (Figure 4), it has proved difficult (Awasaki and Lee, 2011); this has resulted in varied and broad terminology used to describe the diverse population of glia. Here, we categorize larval glia into the same three main groups as embryonic glia; these classes are defined by location, characteristics and function (Freeman, 2015; Hartenstein, 2011; Ou et al., 2014; Stork et al., 2012).

The first group, located in the outer part of the brain, is the SG; this glial type wraps the entire CNS (Figure 4) and acts as a gatekeeper regulating entry into the brain for particles carried within the hemolymph (the fluid analogous to blood in insects). In larvae as in the embryo, this cell population can be divided into PG, the first physical and chemical brain barrier for large particles, and SPG, which communicate amongst themselves via septate junctions and function as an evolutionarily conserved BBB (DeSalvo et al., 2011; Stork et al., 2008). SPG are also in contact with other glial subtypes through adherents or gap junctions (DeSalvo et al., 2011). Hundreds of PG are found per hemisphere and they are smaller in size and have an elongated cell body, while SPG are large with flattened nuclei and are very low in number, around twenty cells per larval hemisphere (Pereanu et al., 2005; Figure 4A and Figure 4B). Ultimately, SG serve as an important mediator between the exterior environment and the interior of the brain (DeSalvo et al., 2011).

A second main glial type, CG, is located underneath the SPG in the larval OLs and is characterised by the expression of the conserved microRNA miR-8 (Morante et al., 2013). In each OL approximately 140 miR- $8^{+}$CG cells enwrap NECs, NBs, GMCs and neurons (Morante et al., 2013; Figure 4B). In the VNC and $C B$ (Figure $4 \mathrm{~A}$ and Figure $4 C$ ), $C G$ also ensheathes NBs and their progeny and are required 
for regulating NB proliferation as well as maintaining energy homeostasis (Chell and Brand, 2010;

A third main glial type, NG, is located between the cortex and the neuropil in the VNC and CB. This glial cell population is the most diverse due to its variety of structures and expression of molecular markers (Pereanu et al., 2005). Although these cells can be named in many different manners depending on their location, they are mainly divided into two subtypes: ensheathing glia (EG) and astrocyte-like glia (ALG; Figure $4 \mathrm{~A}$ and Figure $4 C$ ). EG surround parts of the neuropil whilst ALG manage neural remodelling through axon pruning and synaptic formation (Freeman, 2015; Peco et al., 2016; Tasdemir-Yilmaz and Freeman, 2014; Wu et al., 2017).

In the complexity of the OL, it is possible to distinguish different glial subtypes (Chotard and Salecker, 2007; Huang and Kunes, 1996; Figure 4B). A CG subtype, satellite glia (sg), ensheathes lamina neuron cell bodies. Two subtypes of NG, epithelial glia (eg) and marginal glia (mg), originate in GPC regions and share lineage with lawf neurons (Chen et al., 2016). Later on, both of these subtypes migrate respectively to above (eg) and below ( $\mathrm{mg}$ ) the lamina plexus, into the area where axons of PRs project from the eye imaginal discs (Chotard and Salecker, 2007). Other subtypes of NG are the medulla glia (meg), which are found in the first optic chiasm though their origin is uncertain, and the medulla neuropil glia (mng), which are mainly generated from neuroglioblasts of the OPC and migrate to the anterior cortex-neuropil interface (Li et al., 2013; Richier et al., 2017). Therefore, the wide variety of glial functions, the presence of glia across the entire CNS, and the complexity of glial development strongly suggest that glial cells play an essential role in the brain's regulation and are evolutionarily conserved across species.

\section{Glial-neural progenitor interactions in the developing Drosophila brain}

In recent years, glial cells have been found to play important roles in microenvironments where they can act directly on different biological processes. In adult mammals, the SVZ, where neurogenesis is 
maintained, receives external BBB inputs from diffusible morphogens, the blood or the cerebrospinal fluid (Dani and Lehtinen, 2016; Silva-Vargas et al., 2016). Similarly, in the larval insect brain, the BBB function of the SG layer highlights its importance as a member of a NSC microenvironment (Otsuki and Brand, 2017). SPG and CG cells are known to have large nuclei, as previously mentioned, and also are polyploid; this feature is required to maintain the integrity of the BBB as well as proper growth of SPG cells and the brain in general (Morante et al., 2013; Unhavaithaya and Orr-Weaver, 2012). Additionally, PG cells have been found to be involved in microenvironment signalling. Studies reveal that this SG subtype secretes the signal Dally-like (DIp), a heparan sulfate proteoglycan, which interacts with NBs and acts as a key cue for brain development (Kanai et al., 2018). In return, NBs express Glass bottom boat (Gbb), a BMP homologue, which acts as a survival signal for PG cells as well as an autocrine signal for NBs (Kanai et al., 2018). These recent discoveries suggest that there is still more to be learned about the role of glia in the important processes of development.

Glial cells also act in the larval VNC and CB to reactivate quiescent embryological NBs, providing the source of Drosophila insulin-like peptides (dILPs) relevant for timely reactivation of NBs in response to nutrition (Chell and Brand, 2010; Lanet et al., 2013; Sousa-Nunes et al., 2011). As discovered recently, a VNC NB in the G2 cell cycle phase can enter into quiescence when induced by the evolutionarily conserved pseudokinase Tribbles (Otsuki and Brand, 2018), in contrast to the previously accepted belief that NBs could only arrest at G0. These arrested G2 cells can exit quiescence in the presence of dILP signalling originating from BBB glia, and these cells reactivate and regenerate neurons more quickly than arrested GO NBs; this shows that the stage in which NSCs arrest affects the timing of their reactivation in response to external signals from the glial niche (Otsuki and Brand, 2018). Similarly, it has also been found that dILPs act in the Drosophila visual system as part of a signalling cascade involved in retinotopy. PRs communicate with lamina neurons by producing Spitz/TGF- $\alpha$ (Fernandes et al., 2017; Huang et al., 1998). PR Spitz/TGF- $\alpha$ then acts on wrapping glia, which are part of the peripheral nervous system and in turn produce dILPs which induce LPCS to differentiate into lamina neurons. The role of glia in this essential process 
demonstrates their importance in regulating spatiotemporal differentiation patterns across distinct brain regions (Fernandes et al., 2017; Rossi and Fernandes, 2018). Altogether, these conclusions reinforce the idea that glia have a decisive role in the precursor niche.

NECs are another type of progenitor in which it has been shown that glial ligand expression can significantly influence the development of the $\mathrm{OL}$ in the larval brain. Some examples of this impact on the regulation of NEC proliferation are, for example, the non-autonomous effect that the transmembrane protein Serrate from SPG produces in the Notch pathway (Perez-Gomez et al., 2013) and the influence that the release of Spitz/TGF- $\alpha$ from CG has on the EGF receptor pathway in NECS (Morante et al., 2013).

In addition to glia, NSCs can also send retrograde signals to glia and these local and systemic signals induce the remodelling of CG and help adapt the niche to their needs (Speder and Brand, 2018). The first step of this signalling cascade is the activation of the PI3k/Akt pathway in NSCs via nutritional cues, and this activation causes cortex glia to expand their membrane processes and begin to encase the NSCs. Then, NSCs exit quiescence and resume proliferation, which sends the signal to glial cells to alter the niche according to what is required to restart neurogenesis (Speder and Brand, 2018). In all, recent discoveries have helped elucidate the specific impacts that glial cells may have on neural stem cell niches. However, taking into consideration that glia have an active role in NSC niches, both gliato-progenitor and progenitor-to-glia signalling must be further studied.

\section{The niche in brain injuries and future perspectives}

As previously explained, temporal patterning is an essential mechanism for the development of the brain into such a complex organ. Dysregulation of the TFs important for the transition of neuronal precursors to neurons can lead to brain diseases including malignant tumour formation and loss of neural and glial identity (Maurange and Gould, 2005; Narbonne-Reveau et al., 2016). Additionally, 
defects in the cell polarity of neuroepithelial progenitors may have a direct impact on their offspring and may be involved in tumorigenesis (McCaffrey and Macara, 2011).

Glial cells not only are required for regulating NB proliferation (Chell and Brand, 2010; Lanet et al., 2013; Sousa-Nunes et al., 2011) but also protect NB proliferation in conditions of hypoxia and oxidative stress (Bailey et al., 2015). Dysfunction in glia and their non-autonomous effect on stem cell niches can cause severe problems in the Drosophila brain. It has recently been shown that a glial lineage-specific WDR62 depletion, the second most commonly mutated gene in primary microcephaly, significantly decreased brain volume (Lim et al., 2017). These examples show the importance of relevant function of glia within the stem cell niche.

In conclusion, although a significant amount is already known about progenitor niches and the functions of glial cells in the regulation of neural development, there remains much that has yet to be discovered and more research is required in this field. Scientists should take the opportunity to investigate not only development of each individual element of the stem cell niche but also interactions between the elements, examining the effects that one dysfunctional cell type may have on the other and consequently on the brain as a whole. By combining recent discoveries in Drosophila melanogaster, a powerful model organism, with new studies in mammals, researchers may soon be able to more fully describe the roles of each progenitor type in neurogenesis.

\section{FIGURE LEGENDS:}

Figure 1. Embryonic Neural Progenitors, Cell Division Modes and Progeny in Drosophila melanogaster CNS.

Diagram of neural progenitors and cell division modes described in the CNS of the late embryonic fruit fly. Progenitors and cell division modes are organised by CNS region: (A) the central brain (CB), framed in red; (B) the optic lobe (OL), framed in blue; and (C) the ventral nerve cord (VNC), framed in green. (A1) NBs of the CB: type I, type II (eight cells per hemisphere), and mushroom body (MB) NBs (four cells per hemisphere). (B1) 
Neuroepithelial cells (NECs) and embryonic optic neuroblasts (EONs) in the OL. (C1) NBs of the VNC: type I and

type 0. (A2), (B2) and (C2) show cell division modes in each CNS region of the embryo. In (B2), NECs divide to self-renew before transforming into EONs. GMC: ganglion mother cell, INP: intermediate neural progenitor, n: neuron cell, g: glia cell, NB: neuroblast. The axes indicate A-P (anterior-posterior) and D-V (dorsal-ventral).

\section{Figure 2. Neural Progenitors in Larval CNS in Drosophila melanogaster.}

Diagram of neural progenitors described in CNS of late larval fruit fly. (A) Circled in red, the four types of NBs located in the central brain: type I, type II (eight cells per hemisphere), mushroom body (MB) NBs (four cells per hemisphere), and antennal lobe (AL) NBs (five cells per hemisphere). (B) Circled in blue are the different types of progenitor cells which delaminate from neuroepithelial cells (NECs) of the optic lobe. (B1) shows the NECs of the outer proliferation centre (OPC), which delaminate into type I NBs and lamina precursor cells (LPCs). (B2) shows type 0 NBs of the tip-OPC and common progenitor cells (CPCs), which give rise to glial precursor cells (GPCS) and lamina wide-field precursor cells (Lawf PCs). This section of the figure is shown from a different angle. (B3) shows the NECs of the inner proliferation centre (IPC) that delaminate into migrating progenitors (MPs), which differentiate first into type I and finally into type III NBs. (C) Circled in green, the only NB type (type I) found in the ventral nerve cord. All views are frontal except for (B2), which is seen from a dorsal perspective (for further points of view see figures in Ngo et al. 2017). Note that most of the NBs of the larval CNS originate during the first wave of neurogenesis in the embryonic stage. LF: lamina furrow, $\mathrm{m}$-OPC: medial-OPC, I-OPC: lateral-OPC, p-IPC: proximal-IPC, d-IPC: distal-IPC. The axes indicate A-P (anterior-posterior), D-V (dorsal-ventral) and L-M (lateral-medial).

\section{Figure 3. Neural Progenitor Cell Division Modes and Progeny in Larval CNS in Drosophila melanogaster.}

Representation of all types of NBs (type $0, \mathrm{I}, \mathrm{II}$ and III) and cell progenitors described in the CNS of the late larval fruit fly. The illustration indicates the type of cell division taking place (asymmetric or symmetric) by showing the offspring that each division generates. The progenitors are organized by the CNS region in which they are located: $(A)$ the central brain $(C B)$, framed in red; $(B)$ the optic lobe (OL), framed in blue; and (C) the ventral nerve cord (VNC), framed in green. In (B), NECs divide to self-renew before transforming into progenitor cells. It is important to note that most NBs originate in the first wave of neurogenesis in the embryo. GMC: ganglion mother cell, INP: intermediate neural progenitor, n: neuron cell, g: glia cell, NB: neuroblast, MB: 
mushroom body, AL: antennal lobe, MP: migrating progenitor, LPC: lamina precursor cell, CPC: common progenitor cell, GPC: glia precursor cell, Lawf PC: lamina wide-field precursor cell, NEC: neuroepithelial cell.

Figure 4. Glial Cell Types in Larval CNS of Drosophila melanogaster.

Diagram of distinct glial cell types found in the CNS of the late larval fruit fly. (A) The types of glia found in the central brain, circled in red. The outer surface glia layers are classified as perineural glia (PG), subperineural glia (SPG) and miR8 ${ }^{+}$surface-associated cortex glia (CG), and the neuropil glia (NG) are categorized as ensheathing glia (EG) and astrocyte-like glia (ALG). (B) The optic lobe, circled in blue. PG and SPG are the most external layers of glia, with the $\mathrm{miR}^{+} \mathrm{CG}$ beneath them. Underneath those layers are a CG subtype, satellite glia (sg), and various NG subtypes: epithelial glia (eg), marginal glia (mg), medulla glia (meg) and medulla neuropil glia (mng). (C) Glia in the ventral nerve cord, circled in green. From the outside inward: PG, SPG, CG, EG and ALG. The axes indicate A-P (anterior-posterior) and L-M (lateral-medial).

\section{References}

Alvarez, J.A., and Diaz-Benjumea, F.J. (2018). Origin and specification of type II neuroblasts in the Drosophila embryo. Development 145.

Apitz, H., and Salecker, I. (2015). A region-specific neurogenesis mode requires migratory progenitors in the Drosophila visual system. Nat Neurosci 18, 46-55.

Apitz, H., and Salecker, I. (2018). Spatio-temporal relays control layer identity of direction-selective neuron subtypes in Drosophila. Nature communications 9, 2295.

Awasaki, T., Lai, S.L., Ito, K., and Lee, T. (2008). Organization and postembryonic development of glial cells in the adult central brain of Drosophila. J Neurosci 28, 13742-13753.

Awasaki, T., and Lee, T. (2011). New tools for the analysis of glial cell biology in Drosophila. Glia 59, 1377-1386.

Baek, M., and Mann, R.S. (2009). Lineage and birth date specify motor neuron targeting and dendritic architecture in adult Drosophila. J Neurosci 29, 6904-6916.

Bahrampour, S., Gunnar, E., Jonsson, C., Ekman, H., and Thor, S. (2017). Neural Lineage Progression Controlled by a Temporal Proliferation Program. Dev Cell 43, 332-348 e334.

Bailey, A.P., Koster, G., Guillermier, C., Hirst, E.M., MacRae, J.I., Lechene, C.P., Postle, A.D., and Gould, A.P. (2015). Antioxidant Role for Lipid Droplets in a Stem Cell Niche of Drosophila. Cell 163, 340-353.

Banerjee, S., Mino, R.E., Fisher, E.S., and Bhat, M.A. (2017). A versatile genetic tool to study midline glia function in the Drosophila CNS. Dev Biol 429, 35-43.

Baumgardt, M., Karlsson, D., Salmani, B.Y., Bivik, C., MacDonald, R.B., Gunnar, E., and Thor, S. (2014). Global programmed switch in neural daughter cell proliferation mode triggered by a temporal gene cascade. Dev Cell 30, 192-208.

Baumgardt, M., Karlsson, D., Terriente, J., Diaz-Benjumea, F.J., and Thor, S. (2009). Neuronal subtype specification within a lineage by opposing temporal feed-forward loops. Cell 139, 969-982. 
Baumgardt, M., Miguel-Aliaga, I., Karlsson, D., Ekman, H., and Thor, S. (2007). Specification of neuronal identities by feedforward combinatorial coding. PLoS Biol 5, e37.

Bayraktar, O.A., and Doe, C.Q. (2013). Combinatorial temporal patterning in progenitors expands neural diversity. Nature 498, 449-455.

Beckervordersandforth, R.M., Rickert, C., Altenhein, B., and Technau, G.M. (2008). Subtypes of glial cells in the Drosophila embryonic ventral nerve cord as related to lineage and gene expression. Mech Dev 125, 542-557.

Bellen, H.J., Tong, C., and Tsuda, H. (2010). 100 years of Drosophila research and its impact on vertebrate neuroscience: a history lesson for the future. Nature reviews Neuroscience 11, 514-522. Bello, B.C., Izergina, N., Caussinus, E., and Reichert, H. (2008). Amplification of neural stem cell proliferation by intermediate progenitor cells in Drosophila brain development. Neural Develop 3, 5. Berger, C., Harzer, H., Burkard, T.R., Steinmann, J., van der Horst, S., Laurenson, A.S., Novatchkova, M., Reichert, H., and Knoblich, J.A. (2012). FACS purification and transcriptome analysis of drosophila neural stem cells reveals a role for Klumpfuss in self-renewal. Cell reports 2, 407-418.

Bertet, C., Li, X., Erclik, T., Cavey, M., Wells, B., and Desplan, C. (2014). Temporal patterning of neuroblasts controls Notch-mediated cell survival through regulation of Hid or Reaper. Cell 158, 1173-1186.

Bifari, F., Decimo, I., Pino, A., Llorens-Bobadilla, E., Zhao, S., Lange, C., Panuccio, G., Boeckx, B., Thienpont, B., Vinckier, S., et al. (2017). Neurogenic Radial Glia-like Cells in Meninges Migrate and Differentiate into Functionally Integrated Neurons in the Neonatal Cortex. Cell Stem Cell 20, 360-373 e367.

Bivik, C., Bahrampour, S., Ulvklo, C., Nilsson, P., Angel, A., Fransson, F., Lundin, E., Renhorn, J., and Thor, S. (2015). Novel Genes Involved in Controlling Specification of Drosophila FMRFamide Neuropeptide Cells. Genetics 200, 1229-1244.

Boone, J.Q., and Doe, C.Q. (2008). Identification of Drosophila type II neuroblast lineages containing transit amplifying ganglion mother cells. Dev Neurobiol 68, 1185-1195.

Bossing, T., Udolph, G., Doe, C.Q., and Technau, G.M. (1996). The embryonic central nervous system lineages of Drosophila melanogaster. I. Neuroblast lineages derived from the ventral half of the neuroectoderm. Dev Biol 179, 41-64.

Bowman, S.K., Rolland, V., Betschinger, J., Kinsey, K.A., Emery, G., and Knoblich, J.A. (2008). The Tumor Suppressors Brat and Numb Regulate Transit-Amplifying Neuroblast Lineages in Drosophila. Dev Cell.

Brand, A.H., and Livesey, F.J. (2011). Neural stem cell biology in vertebrates and invertebrates: more alike than different? Neuron 70, 719-729.

Broadus, J., Skeath, J.B., Spana, E.P., Bossing, T., Technau, G., and Doe, C.Q. (1995). New neuroblast markers and the origin of the aCC/pCC neurons in the Drosophila central nervous system. Mech Dev 53, 393-402.

Brody, T., and Odenwald, W.F. (2000). Programmed transformations in neuroblast gene expression during Drosophila CNS lineage development. Dev Biol 226, 34-44.

Buescher, M., Yeo, S.L., Udolph, G., Zavortink, M., Yang, X., Tear, G., and Chia, W. (1998). Binary sibling neuronal cell fate decisions in the Drosophila embryonic central nervous system are nonstochastic and require inscuteable-mediated asymmetry of ganglion mother cells. Genes Dev 12, 1858-1870.

Caygill, E.E., and Brand, A.H. (2017). miR-7 Buffers Differentiation in the Developing Drosophila Visual System. Cell reports 20, 1255-1261.

Ceron, J., Gonzalez, C., and Tejedor, F.J. (2001). Patterns of cell division and expression of asymmetric cell fate determinants in postembryonic neuroblast lineages of Drosophila. Dev Biol 230, 125-138. Chell, J.M., and Brand, A.H. (2010). Nutrition-responsive glia control exit of neural stem cells from quiescence. Cell 143, 1161-1173.

Chen, Z., Del Valle Rodriguez, A., Li, X., Erclik, T., Fernandes, V.M., and Desplan, C. (2016). A Unique Class of Neural Progenitors in the Drosophila Optic Lobe Generates Both Migrating Neurons and Glia. Cell reports 15, 774-786. 
Chotard, C., and Salecker, I. (2007). Glial cell development and function in the Drosophila visual system. Neuron glia biology 3, 17-25.

Clark, M.Q., McCumsey, S.J., Lopez-Darwin, S., Heckscher, E.S., and Doe, C.Q. (2016). Functional Genetic Screen to Identify Interneurons Governing Behaviorally Distinct Aspects of Drosophila Larval Motor Programs. G3 (Bethesda) 6, 2023-2031.

Clark, M.Q., Zarin, A.A., Carreira-Rosario, A., and Doe, C.Q. (2018). Neural circuits driving larval locomotion in Drosophila. Neural Dev 13, 6.

Colonques, J., Ceron, J., and Tejedor, F.J. (2007). Segregation of postembryonic neuronal and glial lineages inferred from a mosaic analysis of the Drosophila larval brain. Mech Dev 124, 327-340. Couton, L., Mauss, A.S., Yunusov, T., Diegelmann, S., Evers, J.F., and Landgraf, M. (2015).

Development of connectivity in a motoneuronal network in Drosophila larvae. Curr Biol 25, 568-576. Dani, N., and Lehtinen, M.K. (2016). CSF Makes Waves in the Neural Stem Cell Niche. Cell Stem Cell 19, 565-566.

Das, A., Gupta, T., Davla, S., Prieto-Godino, L.L., Diegelmann, S., Reddy, O.V., Raghavan, K.V., Reichert, H., Lovick, J., and Hartenstein, V. (2013). Neuroblast lineage-specific origin of the neurons of the Drosophila larval olfactory system. Dev Biol 373, 322-337.

Das, A., Sen, S., Lichtneckert, R., Okada, R., Ito, K., Rodrigues, V., and Reichert, H. (2008). Drosophila olfactory local interneurons and projection neurons derive from a common neuroblast lineage specified by the empty spiracles gene. Neural Dev 3, 33.

Delaunay, D., Kawaguchi, A., Dehay, C., and Matsuzaki, F. (2017). Division modes and physical asymmetry in cerebral cortex progenitors. Curr Opin Neurobiol 42, 75-83.

DeSalvo, M.K., Hindle, S.J., Rusan, Z.M., Orng, S., Eddison, M., Halliwill, K., and Bainton, R.J. (2014). The Drosophila surface glia transcriptome: evolutionary conserved blood-brain barrier processes. Front Neurosci 8, 346.

DeSalvo, M.K., Mayer, N., Mayer, F., and Bainton, R.J. (2011). Physiologic and anatomic characterization of the brain surface glia barrier of Drosophila. Glia 59, 1322-1340.

Doe, C.Q. (2017). Temporal Patterning in the Drosophila CNS. Annu Rev Cell Dev Biol 33, 219-240. Droujinine, I.A., and Perrimon, N. (2016). Interorgan Communication Pathways in Physiology: Focus on Drosophila. Annu Rev Genet 50, 539-570.

Egger, B., Boone, J.Q., Stevens, N.R., Brand, A.H., and Doe, C.Q. (2007). Regulation of spindle orientation and neural stem cell fate in the Drosophila optic lobe. Neural Develop 2, 1.

Egger, B., Gold, K.S., and Brand, A.H. (2010). Notch regulates the switch from symmetric to asymmetric neural stem cell division in the Drosophila optic lobe. Development 137, 2981-2987. Elliott, J., Jolicoeur, C., Ramamurthy, V., and Cayouette, M. (2008). Ikaros confers early temporal competence to mouse retinal progenitor cells. Neuron 60, 26-39.

Enriquez, J., Rio, L.Q., Blazeski, R., Bellemin, S., Godement, P., Mason, C., and Mann, R.S. (2018). Differing Strategies Despite Shared Lineages of Motor Neurons and Glia to Achieve Robust Development of an Adult Neuropil in Drosophila. Neuron 97, 538-554 e535.

Erclik, T., Hartenstein, V., Lipshitz, H.D., and Mclnnes, R.R. (2008). Conserved role of the Vsx genes supports a monophyletic origin for bilaterian visual systems. Curr Biol 18, 1278-1287.

Erclik, T., Li, X., Courgeon, M., Bertet, C., Chen, Z., Baumert, R., Ng, J., Koo, C., Arain, U., Behnia, R., et al. (2017). Integration of temporal and spatial patterning generates neural diversity. Nature $541,365-$ 370.

Fernandes, V.M., Chen, Z., Rossi, A.M., Zipfel, J., and Desplan, C. (2017). Glia relay differentiation cues to coordinate neuronal development in Drosophila. Science 357, 886-891.

Fernandez, V., Llinares-Benadero, C., and Borrell, V. (2016). Cerebral cortex expansion and folding: what have we learned? EMBO J 35, 1021-1044.

Ferraro, F., Celso, C.L., and Scadden, D. (2010). Adult stem cels and their niches. Adv Exp Med Biol 695, 155-168.

Fischbach, K.F., and Dittrich, A.P.M. (1989). The optic lobe of Drosophila melanogaster. I. A Golgi analysis of wild-type structure. Cell Tissue Res 258, 441-475. 
Franzdottir, S.R., Engelen, D., Yuva-Aydemir, Y., Schmidt, I., Aho, A., and Klambt, C. (2009). Switch in FGF signalling initiates glial differentiation in the Drosophila eye. Nature 460, 758-761.

Freeman, M.R. (2015). Drosophila Central Nervous System Glia. Cold Spring Harb Perspect Biol 7. Freeman, M.R., Delrow, J., Kim, J., Johnson, E., and Doe, C.Q. (2003). Unwrapping glial biology: Gcm target genes regulating glial development, diversification, and function. Neuron 38, 567-580.

Freeman, M.R., and Doherty, J. (2006). Glial cell biology in Drosophila and vertebrates. Trends Neurosci 29, 82-90.

Gaiano, N., and Fishell, G. (2002). The role of notch in promoting glial and neural stem cell fates. Annu Rev Neurosci 25, 471-490.

Gerstein, M.B., Rozowsky, J., Yan, K.K., Wang, D., Cheng, C., Brown, J.B., Davis, C.A., Hillier, L., Sisu, C., Li, J.J., et al. (2014). Comparative analysis of the transcriptome across distant species. Nature 512, 445-448.

Gold, K.S., and Brand, A.H. (2014). Optix defines a neuroepithelial compartment in the optic lobe of the Drosophila brain. Neural Dev 9, 18.

Gotz, M., and Huttner, W.B. (2005). The cell biology of neurogenesis. Nat Rev Mol Cell Biol 6, 777788.

Gratz, S.J., Cummings, A.M., Nguyen, J.N., Hamm, D.C., Donohue, L.K., Harrison, M.M., Wildonger, J., and O'Connor-Giles, K.M. (2013). Genome engineering of Drosophila with the CRISPR RNA-guided Cas9 nuclease. Genetics 194, 1029-1035.

Grosskortenhaus, R., Pearson, B.J., Marusich, A., and Doe, C.Q. (2005). Regulation of temporal identity transitions in Drosophila neuroblasts. Dev Cell 8, 193-202.

Hakes, A.E., Otsuki, L., and Brand, A.H. (2018). A newly discovered neural stem cell population is generated by the optic lobe neuroepithelium during embryogenesis in Drosophila melanogaster. Development 145.

Hartenstein, V. (2011). Morphological diversity and development of glia in Drosophila. Glia 59, 12371252.

Hartenstein, V., Nassif, C., and Lekven, A. (1998). Embryonic development of the Drosophila brain. II. Pattern of glial cells. J Comp Neurol 402, 32-47.

Hartenstein, V., Younossi-Hartenstein, A., and Lekven, A. (1994). Delamination and division in the Drosophila neurectoderm: spatiotemporal pattern, cytoskeletal dynamics, and common control by neurogenic and segment polarity genes. Dev Biol 165, 480-499.

Hasegawa, E., Kitada, Y., Kaido, M., Takayama, R., Awasaki, T., Tabata, T., and Sato, M. (2011). Concentric zones, cell migration and neuronal circuits in the Drosophila visual center. Development 138, 983-993.

Heckscher, E.S., Zarin, A.A., Faumont, S., Clark, M.Q., Manning, L., Fushiki, A., Schneider-Mizell, C.M., Fetter, R.D., Truman, J.W., Zwart, M.F., et al. (2015). Even-Skipped(+) Interneurons Are Core Components of a Sensorimotor Circuit that Maintains Left-Right Symmetric Muscle Contraction Amplitude. Neuron 88, 314-329.

Hofbauer, A., and Campos-Ortega, J.A. (1990). Proliferation pattern and early differentiation of the optic lobes in Drosophila melanogaster. Rouxs Arch Dev Biol 198, 264-274.

Holguera, I., and Desplan, C. (2018). Neuronal specification in space and time. Science 362, 176-180. Homem, C.C., and Knoblich, J.A. (2012). Drosophila neuroblasts: a model for stem cell biology. Development 139, 4297-4310.

Hosoya, T., Takizawa, K., Nitta, K., and Hotta, Y. (1995). glial cells missing: a binary switch between neuronal and glial determination in Drosophila. Cell 82, 1025-1036.

Huang, Z., and Kunes, S. (1996). Hedgehog, transmitted along retinal axons, triggers neurogenesis in the developing visual centers of the Drosophila brain. Cell 86, 411-422.

Huang, Z., and Kunes, S. (1998). Signals transmitted along retinal axons in Drosophila: Hedgehog signal reception and the cell circuitry of lamina cartridge assembly. Development 125, 3753-3764.

Huang, Z., Shilo, B.Z., and Kunes, S. (1998). A retinal axon fascicle uses spitz, an EGF receptor ligand, to construct a synaptic cartridge in the brain of Drosophila. Cell 95, 693-703. 
Isshiki, T., Pearson, B., Holbrook, S., and Doe, C.Q. (2001). Drosophila neuroblasts sequentially express transcription factors which specify the temporal identity of their neuronal progeny. Cell 106, 511-521.

Ito, K., Urban, J., and Technau, G. (1995). Distribution, classification, and development of Drosophila glial cells in the late embryonic and early larval ventral nerve cord. Roux's Archive in Developmental Biology 204, 284-307.

Ito, M., Masuda, N., Shinomiya, K., Endo, K., and Ito, K. (2013). Systematic analysis of neural projections reveals clonal composition of the Drosophila brain. Curr Biol 23, 644-655.

Izergina, N., Balmer, J., Bello, B., and Reichert, H. (2009). Postembryonic development of transit amplifying neuroblast lineages in the Drosophila brain. Neural Dev 4, 44.

Jacobs, J.R. (2000). The midline glia of Drosophila: a molecular genetic model for the developmental functions of glia. Prog Neurobiol 62, 475-508.

Jefferis, G.S., Marin, E.C., Stocker, R.F., and Luo, L. (2001). Target neuron prespecification in the olfactory map of Drosophila. Nature 414, 204-208.

Jones, B.W., Fetter, R.D., Tear, G., and Goodman, C.S. (1995). glial cells missing: a genetic switch that controls glial versus neuronal fate. Cell 82, 1013-1023.

Kambadur, R., Koizumi, K., Stivers, C., Nagle, J., Poole, S.J., and Odenwald, W.F. (1998). Regulation of POU genes by castor and hunchback establishes layered compartments in the Drosophila CNS. Genes Dev 12, 246-260.

Kanai, M.I., Kim, M.J., Akiyama, T., Takemura, M., Wharton, K., O'Connor, M.B., and Nakato, H. (2018). Regulation of neuroblast proliferation by surface glia in the Drosophila larval brain. Sci Rep 8 , 3730.

Kanai, M.I., Okabe, M., and Hiromi, Y. (2005). seven-up Controls switching of transcription factors that specify temporal identities of Drosophila neuroblasts. Dev Cell 8, 203-213.

Kim, M.D., Wen, Y., and Jan, Y.N. (2009). Patterning and organization of motor neuron dendrites in the Drosophila larva. Dev Biol 336, 213-221.

Knoblich, J.A. (2008). Mechanisms of asymmetric stem cell division. Cell 132, 583-597.

Kohwi, M., and Doe, C.Q. (2013). Temporal fate specification and neural progenitor competence during development. Nature reviews Neuroscience 14, 823-838.

Kohwi, M., Hiebert, L.S., and Doe, C.Q. (2011). The pipsqueak-domain proteins Distal antenna and Distal antenna-related restrict Hunchback neuroblast expression and early-born neuronal identity. Development 138, 1727-1735.

Kriegstein, A., and Alvarez-Buylla, A. (2009). The glial nature of embryonic and adult neural stem cells. Annu Rev Neurosci 32, 149-184.

Kunz, T., Kraft, K.F., Technau, G.M., and Urbach, R. (2012). Origin of Drosophila mushroom body neuroblasts and generation of divergent embryonic lineages. Development 139, 2510-2522.

Lai, S.L., Awasaki, T., Ito, K., and Lee, T. (2008). Clonal analysis of Drosophila antennal lobe neurons: diverse neuronal architectures in the lateral neuroblast lineage. Development 135, 2883-2893. Landgraf, M., and Thor, S. (2006). Development of Drosophila motoneurons: specification and morphology. Semin Cell Dev Biol 17, 3-11.

Lanet, E., Gould, A.P., and Maurange, C. (2013). Protection of Neuronal Diversity at the Expense of Neuronal Numbers during Nutrient Restriction in the Drosophila Visual System. Cell reports.

Larsen, C., Shy, D., Spindler, S.R., Fung, S., Pereanu, W., Younossi-Hartenstein, A., and Hartenstein, V. (2009). Patterns of growth, axonal extension and axonal arborization of neuronal lineages in the developing Drosophila brain. Dev Biol 335, 289-304.

Lee, T., Lee, A., and Luo, L. (1999). Development of the Drosophila mushroom bodies: sequential generation of three distinct types of neurons from a neuroblast. Development 126, 4065-4076.

Lehtinen, M.K., and Walsh, C.A. (2011). Neurogenesis at the brain-cerebrospinal fluid interface. Annu Rev Cell Dev Biol 27, 653-679.

Lehtinen, M.K., Zappaterra, M.W., Chen, X., Yang, Y.J., Hill, A.D., Lun, M., Maynard, T., Gonzalez, D., Kim, S., Ye, P., et al. (2011). The cerebrospinal fluid provides a proliferative niche for neural progenitor cells. Neuron 69, 893-905. 
Li, X., Erclik, T., Bertet, C., Chen, Z., Voutev, R., Venkatesh, S., Morante, J., Celik, A., and Desplan, C. (2013). Temporal patterning of Drosophila medulla neuroblasts controls neural fates. Nature 498, 456-462.

Lim, N.R., Shohayeb, B., Zaytseva, O., Mitchell, N., Millard, S.S., Ng, D.C.H., and Quinn, L.M. (2017). Glial-Specific Functions of Microcephaly Protein WDR62 and Interaction with the Mitotic Kinase AURKA Are Essential for Drosophila Brain Growth. Stem Cell Reports 9, 32-41.

Lin, S., Kao, C.F., Yu, H.H., Huang, Y., and Lee, T. (2012). Lineage analysis of Drosophila lateral antennal lobe neurons reveals notch-dependent binary temporal fate decisions. PLoS Biol 10, e1001425.

Lin, S., Lai, S.L., Yu, H.H., Chihara, T., Luo, L., and Lee, T. (2010). Lineage-specific effects of Notch/Numb signaling in post-embryonic development of the Drosophila brain. Development 137, 43-51.

Liu, Z., Yang, C.P., Sugino, K., Fu, C.C., Liu, L.Y., Yao, X., Lee, L.P., and Lee, T. (2015). Opposing intrinsic temporal gradients guide neural stem cell production of varied neuronal fates. Science 350, 317-320. Manning, L., and Doe, C.Q. (2017). Immunofluorescent antibody staining of intact Drosophila larvae. Nat Protoc 12, 1-14.

Marin, E.C., Jefferis, G.S., Komiyama, T., Zhu, H., and Luo, L. (2002). Representation of the glomerular olfactory map in the Drosophila brain. Cell 109, 243-255.

Marin, E.C., Watts, R.J., Tanaka, N.K., Ito, K., and Luo, L. (2005). Developmentally programmed remodeling of the Drosophila olfactory circuit. Development 132, 725-737.

Maurange, C. (2012). Temporal specification of neural stem cells: insights from Drosophila neuroblasts. Curr Top Dev Biol 98, 199-228.

Maurange, C., Cheng, L., and Gould, A.P. (2008). Temporal transcription factors and their targets schedule the end of neural proliferation in Drosophila. Cell 133, 891-902.

Maurange, C., and Gould, A.P. (2005). Brainy but not too brainy: starting and stopping neuroblast divisions in Drosophila. Trends Neurosci 28, 30-36.

McCaffrey, L.M., and Macara, I.G. (2011). Epithelial organization, cell polarity and tumorigenesis. Trends Cell Biol 21, 727-735.

Meinertzhagen, I.A., and Hanson, T.E. (1993). The Development of the Optic Lobe. The Development of Drosophila melanogaster 2, 1363-1491.

Mettler, U., Vogler, G., and Urban, J. (2006). Timing of identity: spatiotemporal regulation of hunchback in neuroblast lineages of Drosophila by Seven-up and Prospero. Development 133, 429437.

Monedero Cobeta, I., Salmani, B.Y., and Thor, S. (2017). Anterior-Posterior Gradient in Neural Stem and Daughter Cell Proliferation Governed by Spatial and Temporal Hox Control. Curr Biol 27, 11611172.

Mora, N., Oliva, C., Fiers, M., Ejsmont, R., Soldano, A., Zhang, T.T., Yan, J., Claeys, A., De Geest, N., and Hassan, B.A. (2018). A Temporal Transcriptional Switch Governs Stem Cell Division, Neuronal Numbers, and Maintenance of Differentiation. Dev Cell 45, 53-66 e55.

Morante, J., and Desplan, C. (2004). Building a projection map for photoreceptor neurons in the Drosophila optic lobes. Semin Cell Dev Biol 15, 137-143.

Morante, J., and Desplan, C. (2011). Dissection and staining of Drosophila optic lobes at different stages of development. Cold Spring Harb Protoc 2011, 652-656.

Morante, J., Erclik, T., and Desplan, C. (2011). Cell migration in Drosophila optic lobe neurons is controlled by eyeless/Pax6. Development 138, 687-693.

Morante, J., Vallejo, D.M., Desplan, C., and Dominguez, M. (2013). Conserved miR-8/miR-200 defines a glial niche that controls neuroepithelial expansion and neuroblast transition. Dev Cell 27, 174-187.

Moris-Sanz, M., Estacio-Gomez, A., Alvarez-Rivero, J., and Diaz-Benjumea, F.J. (2014). Specification of neuronal subtypes by different levels of Hunchback. Development 141, 4366-4374.

Morrison, S.J., and Spradling, A.C. (2008). Stem cells and niches: mechanisms that promote stem cell maintenance throughout life. Cell 132, 598-611. 
Narbonne-Reveau, K., Lanet, E., Dillard, C., Foppolo, S., Chen, C.H., Parrinello, H., Rialle, S., Sokol, N.S., and Maurange, C. (2016). Neural stem cell-encoded temporal patterning delineates an early window of malignant susceptibility in Drosophila. eLife 5.

Ngo, K.T., Wang, J., Junker, M., Kriz, S., Vo, G., Asem, B., Olson, J.M., Banerjee, U., and Hartenstein, V. (2010). Concomitant requirement for Notch and Jak/Stat signaling during neuro-epithelial differentiation in the Drosophila optic lobe. Dev Biol 346, 284-295.

Obernier, K., Cebrian-Silla, A., Thomson, M., Parraguez, J.I., Anderson, R., Guinto, C., Rodas Rodriguez, J., Garcia-Verdugo, J.M., and Alvarez-Buylla, A. (2018). Adult Neurogenesis Is Sustained by Symmetric Self-Renewal and Differentiation. Cell Stem Cell 22, 221-234 e228.

Okamoto, M., Miyata, T., Konno, D., Ueda, H.R., Kasukawa, T., Hashimoto, M., Matsuzaki, F., and Kawaguchi, A. (2016). Cell-cycle-independent transitions in temporal identity of mammalian neural progenitor cells. Nature communications $7,11349$.

Okamoto, N., and Nishimura, T. (2015). Signaling from Glia and Cholinergic Neurons Controls Nutrient-Dependent Production of an Insulin-like Peptide for Drosophila Body Growth. Dev Cell 35, 295-310.

Oliva, C., Choi, C.M., Nicolai, L.J., Mora, N., De Geest, N., and Hassan, B.A. (2014). Proper connectivity of Drosophila motion detector neurons requires Atonal function in progenitor cells. Neural Dev 9, 4. Omoto, J.J., Yogi, P., and Hartenstein, V. (2015). Origin and development of neuropil glia of the Drosophila larval and adult brain: Two distinct glial populations derived from separate progenitors. Dev Biol 404, 2-20.

Otsuki, L., and Brand, A.H. (2017). The vasculature as a neural stem cell niche. Neurobiology of disease 107, 4-14.

Otsuki, L., and Brand, A.H. (2018). Cell cycle heterogeneity directs the timing of neural stem cell activation from quiescence. Science 360, 99-102.

Ou, J., Gao, Z., Song, L., and Ho, M.S. (2016). Analysis of Glial Distribution in Drosophila Adult Brains. Neurosci Bull 32, 162-170.

Ou, J., He, Y., Xiao, X., Yu, T.M., Chen, C., Gao, Z., and Ho, M.S. (2014). Glial cells in neuronal development: recent advances and insights from Drosophila melanogaster. Neurosci Bull 30, 584594.

Paridaen, J.T., and Huttner, W.B. (2014). Neurogenesis during development of the vertebrate central nervous system. EMBO Rep 15, 351-364.

Peco, E., Davla, S., Camp, D., Stacey, S.M., Landgraf, M., and van Meyel, D.J. (2016). Drosophila astrocytes cover specific territories of the CNS neuropil and are instructed to differentiate by Prospero, a key effector of Notch. Development 143, 1170-1181.

Pereanu, W., Shy, D., and Hartenstein, V. (2005). Morphogenesis and proliferation of the larval brain glia in Drosophila. Dev Biol 283, 191-203.

Perez-Gomez, R., Slovakova, J., Rives-Quinto, N., Krejci, A., and Carmena, A. (2013). A Serrate-NotchCanoe complex mediates essential interactions between glia and neuroepithelial cells during Drosophila optic lobe development. J Cell Sci 126, 4873-4884.

Pinto-Teixeira, F., Koo, C., Rossi, A.M., Neriec, N., Bertet, C., Li, X., Del-Valle-Rodriguez, A., and Desplan, C. (2018). Development of Concurrent Retinotopic Maps in the Fly Motion Detection Circuit. Cell 173, 485-498 e411.

Ramaekers, A., Magnenat, E., Marin, E.C., Gendre, N., Jefferis, G.S., Luo, L., and Stocker, R.F. (2005). Glomerular maps without cellular redundancy at successive levels of the Drosophila larval olfactory circuit. Curr Biol 15, 982-992.

Reddy, B.V., Rauskolb, C., and Irvine, K.D. (2010). Influence of fat-hippo and notch signaling on the proliferation and differentiation of Drosophila optic neuroepithelia. Development 137, 2397-2408. Ren, Q., Yang, C.P., Liu, Z., Sugino, K., Mok, K., He, Y., Ito, M., Nern, A., Otsuna, H., and Lee, T. (2017). Stem Cell-Intrinsic, Seven-up-Triggered Temporal Factor Gradients Diversify Intermediate Neural Progenitors. Curr Biol 27, 1303-1313.

Richier, B., Vijandi, C.M., Mackensen, S., and Salecker, I. (2017). Lapsyn controls branch extension and positioning of astrocyte-like glia in the Drosophila optic lobe. Nature communications 8, 317. 
Rossi, A.M., and Fernandes, V.M. (2018). Wrapping Glial Morphogenesis and Signaling Control the Timing and Pattern of Neuronal Differentiation in the Drosophila Lamina. J Exp Neurosci 12, 1179069518759294.

Rowitch, D.H., and Kriegstein, A.R. (2010). Developmental genetics of vertebrate glial-cell specification. Nature 468, 214-222.

Sarov, M., Barz, C., Jambor, H., Hein, M.Y., Schmied, C., Suchold, D., Stender, B., Janosch, S., K, J.V., Krishnan, R.T., et al. (2016). A genome-wide resource for the analysis of protein localisation in Drosophila. eLife 5, e12068.

Sato, M., Suzuki, T., and Nakai, Y. (2013). Waves of differentiation in the fly visual system. Dev Biol 380, 1-11.

Schmidt, H., Rickert, C., Bossing, T., Vef, O., Urban, J., and Technau, G.M. (1997). The embryonic central nervous system lineages of Drosophila melanogaster. II. Neuroblast lineages derived from the dorsal part of the neuroectoderm. Dev Biol 189, 186-204.

Selleck, S.B., and Steller, H. (1991). The influence of retinal innervation on neurogenesis in the first optic ganglion of Drosophila. Neuron 6, 83-99.

Siegenthaler, J.A., Ashique, A.M., Zarbalis, K., Patterson, K.P., Hecht, J.H., Kane, M.A., Folias, A.E., Choe, Y., May, S.R., Kume, T., et al. (2009). Retinoic acid from the meninges regulates cortical neuron generation. Cell 139, 597-609.

Siegenthaler, J.A., and Pleasure, S.J. (2011). We have got you 'covered': how the meninges control brain development. Curr Opin Genet Dev 21, 249-255.

Silva-Vargas, V., Maldonado-Soto, A.R., Mizrak, D., Codega, P., and Doetsch, F. (2016). Age-

Dependent Niche Signals from the Choroid Plexus Regulate Adult Neural Stem Cells. Cell Stem Cell 19, 643-652.

Sousa-Nunes, R., Cheng, L.Y., and Gould, A.P. (2010). Regulating neural proliferation in the Drosophila CNS. Curr Opin Neurobiol 20, 50-57.

Sousa-Nunes, R., Yee, L.L., and Gould, A.P. (2011). Fat cells reactivate quiescent neuroblasts via TOR and glial insulin relays in Drosophila. Nature 471, 508-512.

Speder, P., and Brand, A.H. (2018). Systemic and local cues drive neural stem cell niche remodelling during neurogenesis in Drosophila. eLife 7.

Speder, P., Liu, J., and Brand, A.H. (2011). Nutrient control of neural stem cells. Curr Opin Cell Biol 23, 724-729.

Stork, T., Bernardos, R., and Freeman, M.R. (2012). Analysis of glial cell development and function in Drosophila. Cold Spring Harb Protoc 2012, 1-17.

Stork, T., Engelen, D., Krudewig, A., Silies, M., Bainton, R.J., and Klambt, C. (2008). Organization and function of the blood-brain barrier in Drosophila. J Neurosci 28, 587-597.

Suzuki, T., Hasegawa, E., Nakai, Y., Kaido, M., Takayama, R., and Sato, M. (2016). Formation of Neuronal Circuits by Interactions between Neuronal Populations Derived from Different Origins in the Drosophila Visual Center. Cell reports 15, 499-509.

Suzuki, T., Kaido, M., Takayama, R., and Sato, M. (2013). A temporal mechanism that produces neuronal diversity in the Drosophila visual center. Dev Biol 380, 12-24.

Syed, M.H., Mark, B., and Doe, C.Q. (2017a). Playing Well with Others: Extrinsic Cues Regulate Neural Progenitor Temporal Identity to Generate Neuronal Diversity. Trends Genet 33, 933-942.

Syed, M.H., Mark, B., and Doe, C.Q. (2017b). Steroid hormone induction of temporal gene expression in Drosophila brain neuroblasts generates neuronal and glial diversity. eLife 6.

Tasdemir-Yilmaz, O.E., and Freeman, M.R. (2014). Astrocytes engage unique molecular programs to engulf pruned neuronal debris from distinct subsets of neurons. Genes Dev 28, 20-33.

Taylor, M.K., Yeager, K., and Morrison, S.J. (2007). Physiological Notch signaling promotes gliogenesis in the developing peripheral and central nervous systems. Development 134, 2435-2447.

Tiberi, L., Vanderhaeghen, P., and van den Ameele, J. (2012). Cortical neurogenesis and morphogens: diversity of cues, sources and functions. Curr Opin Cell Biol 24, 269-276.

Truman, J.W., and Bate, M. (1988). Spatial and temporal patterns of neurogenesis in the central nervous system of Drosophila melanogaster. Dev Biol 125, 145-157. 
Ugur, B., Chen, K., and Bellen, H.J. (2016). Drosophila tools and assays for the study of human diseases. Dis Model Mech 9, 235-244.

Ulvklo, C., MacDonald, R., Bivik, C., Baumgardt, M., Karlsson, D., and Thor, S. (2012). Control of neuronal cell fate and number by integration of distinct daughter cell proliferation modes with temporal progression. Development 139, 678-689.

Unhavaithaya, Y., and Orr-Weaver, T.L. (2012). Polyploidization of glia in neural development links tissue growth to blood-brain barrier integrity. Genes Dev 26, 31-36.

Urbach, R., Schnabel, R., and Technau, G.M. (2003). The pattern of neuroblast formation, mitotic domains and proneural gene expression during early brain development in Drosophila. Development 130, 3589-3606.

Urbach, R., and Technau, G.M. (2004). Neuroblast formation and patterning during early brain development in Drosophila. Bioessays 26, 739-751.

Van De Bor, V., and Giangrande, A. (2002). glide/gcm: at the crossroads between neurons and glia. Curr Opin Genet Dev 12, 465-472.

Viktorin, G., Riebli, N., and Reichert, H. (2013). A multipotent transit-amplifying neuroblast lineage in the central brain gives rise to optic lobe glial cells in Drosophila. Dev Biol 379, 182-194.

Volkenhoff, A., Weiler, A., Letzel, M., Stehling, M., Klambt, C., and Schirmeier, S. (2015). Glial Glycolysis Is Essential for Neuronal Survival in Drosophila. Cell metabolism 22, 437-447.

von Hilchen, C.M., Beckervordersandforth, R.M., Rickert, C., Technau, G.M., and Altenhein, B. (2008). Identity, origin, and migration of peripheral glial cells in the Drosophila embryo. Mech Dev 125, 337352.

Vosshall, L.B., Wong, A.M., and Axel, R. (2000). An olfactory sensory map in the fly brain. Cell 102, 147-159.

Walsh, K.T., and Doe, C.Q. (2017). Drosophila embryonic type II neuroblasts: origin, temporal patterning, and contribution to the adult central complex. Development 144, 4552-4562.

White, K., Grether, M.E., Abrams, J.M., Young, L., Farrell, K., and Steller, H. (1994). Genetic control of programmed cell death in Drosophila [see comments]. Science 264, 677-683.

Winberg, M.L., Perez, S.E., and Steller, H. (1992). Generation and early differentiation of glial cells in the first optic ganglion of Drosophila melanogaster. Development 115, 903-911.

Wu, B., Li, J., Chou, Y.H., Luginbuhl, D., and Luo, L. (2017). Fibroblast growth factor signaling instructs ensheathing glia wrapping of Drosophila olfactory glomeruli. Proc Natl Acad Sci U S A 114, 75057512.

Xie, Y., Li, X., Deng, X., Hou, Y., O'Hara, K., Urso, A., Peng, Y., Chen, L., and Zhu, S. (2016). The Ets protein Pointed prevents both premature differentiation and dedifferentiation of Drosophila intermediate neural progenitors. Development 143, 3109-3118.

Yaghmaeian Salmani, B., Monedero Cobeta, I., Rakar, J., Bauer, S., Curt, J.R., Starkenberg, A., and Thor, S. (2018). Evolutionarily conserved anterior expansion of the central nervous system promoted by a common PcG-Hox program. Development 145.

Yang, J.S., Awasaki, T., Yu, H.H., He, Y., Ding, P., Kao, J.C., and Lee, T. (2013). Diverse neuronal lineages make stereotyped contributions to the Drosophila locomotor control center, the central complex. J Comp Neurol 521, 2645-Spc2641.

Yasugi, T., Sugie, A., Umetsu, D., and Tabata, T. (2010). Coordinated sequential action of EGFR and Notch signaling pathways regulates proneural wave progression in the Drosophila optic lobe.

Development 137, 3193-3203.

Yasugi, T., Umetsu, D., Murakami, S., Sato, M., and Tabata, T. (2008). Drosophila optic lobe neuroblasts triggered by a wave of proneural gene expression that is negatively regulated by JAK/STAT. Development 135, 1471-1480.

Yu, H.H., Awasaki, T., Schroeder, M.D., Long, F., Yang, J.S., He, Y., Ding, P., Kao, J.C., Wu, G.Y., Peng, $H_{.}$, et al. (2013). Clonal development and organization of the adult Drosophila central brain. Curr Biol 23, 633-643.

Yu, H.H., Kao, C.F., He, Y., Ding, P., Kao, J.C., and Lee, T. (2010). A complete developmental sequence of a Drosophila neuronal lineage as revealed by twin-spot MARCM. PLoS Biol 8. 
Zhu, S., Barshow, S., Wildonger, J., Jan, L.Y., and Jan, Y.N. (2011). Ets transcription factor Pointed promotes the generation of intermediate neural progenitors in Drosophila larval brains. Proc Natl Acad Sci U S A 108, 20615-20620.

Zhu, S., Lin, S., Kao, C.F., Awasaki, T., Chiang, A.S., and Lee, T. (2006). Gradients of the Drosophila Chinmo BTB-zinc finger protein govern neuronal temporal identity. Cell 127, 409-422.

Zuchero, J.B., and Barres, B.A. (2015). Glia in mammalian development and disease. Development 142, 3805-3809. 
Figure 1
Click here to download high resolution image
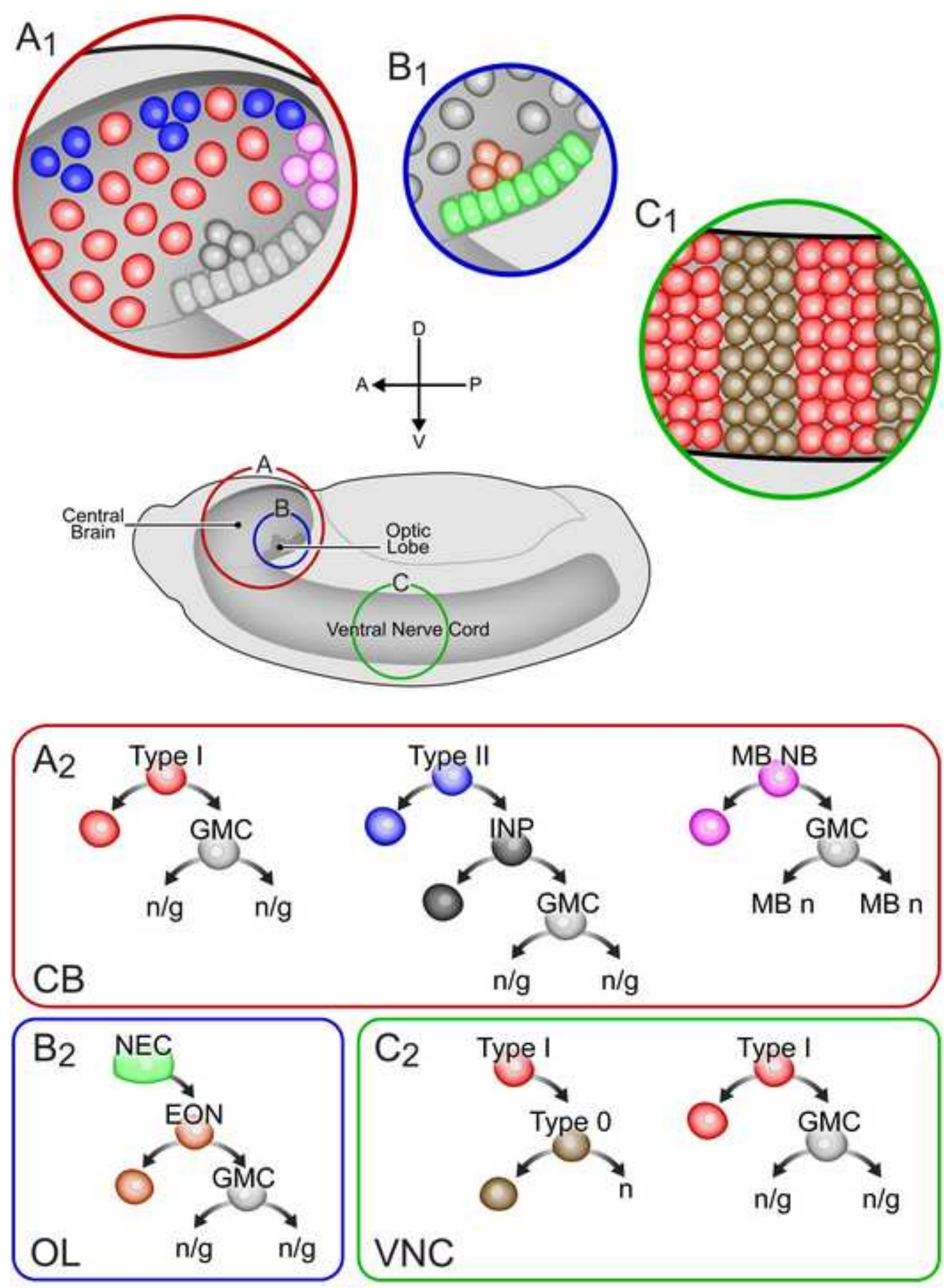

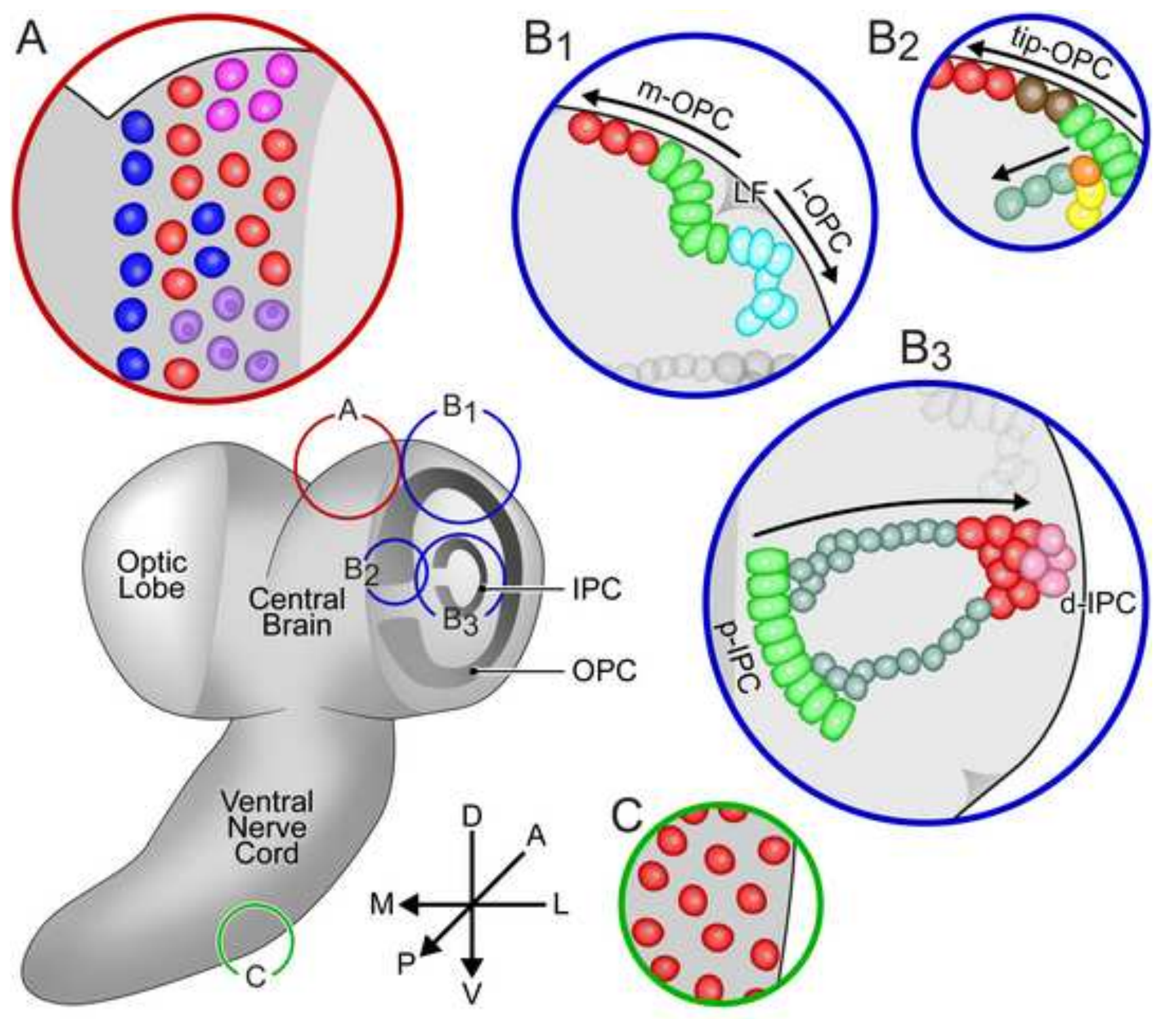

OPC

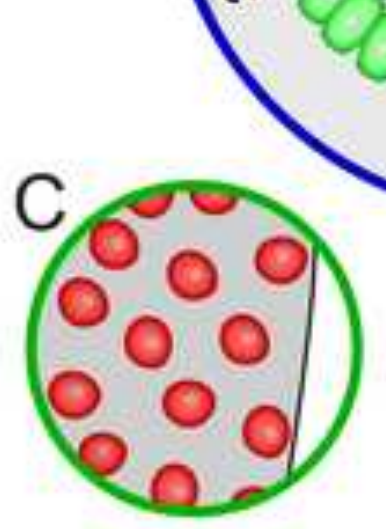

NEC O Type 0 NB O Type I NB O Type II NB O Type III NB O MB NB (1) ALB $\bigcirc \mathrm{MP} \bigcirc \mathrm{LPC} \bigcirc \mathrm{CPC} \odot \mathrm{GPC} \odot$ Lawf PC 

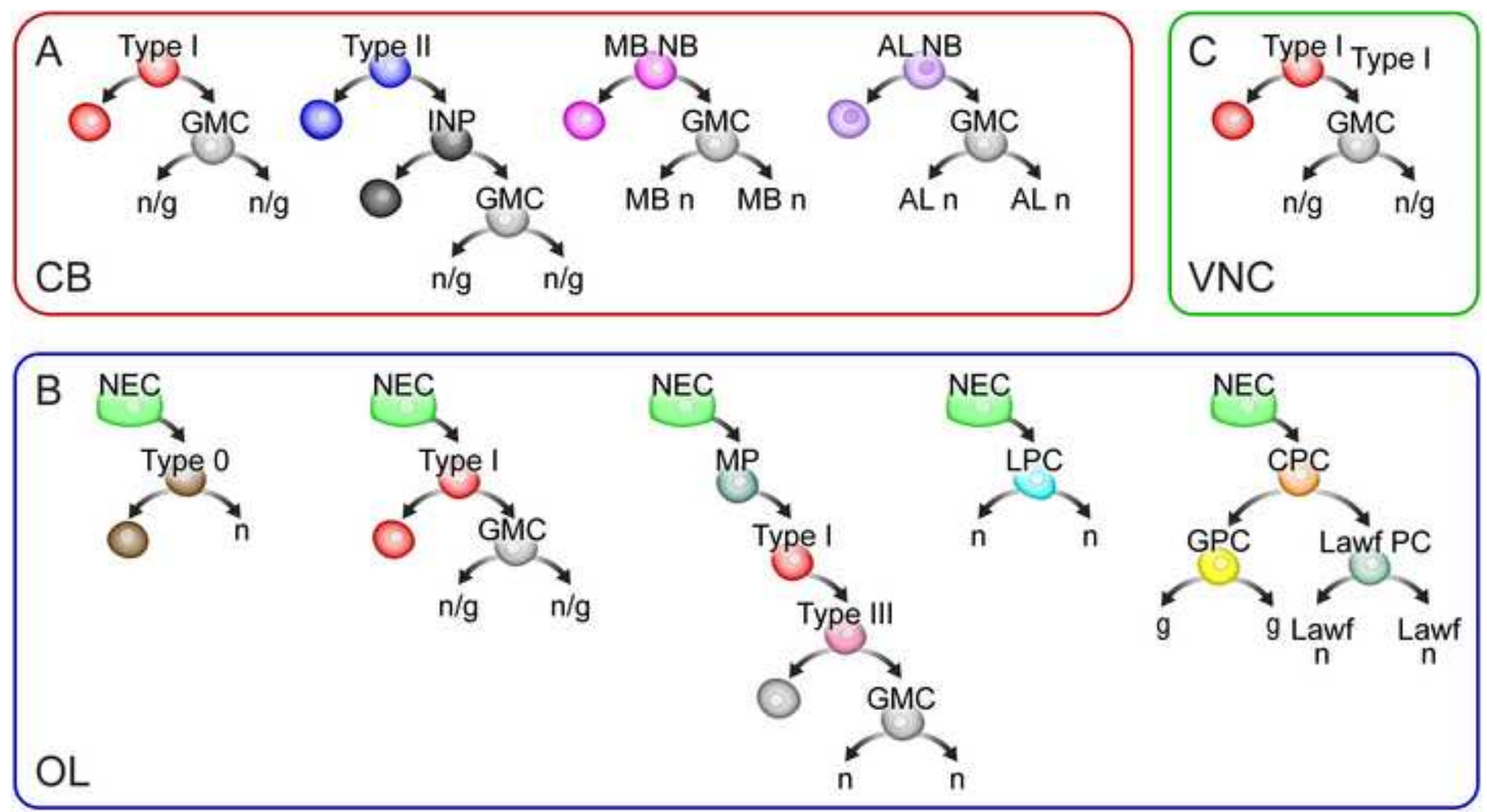


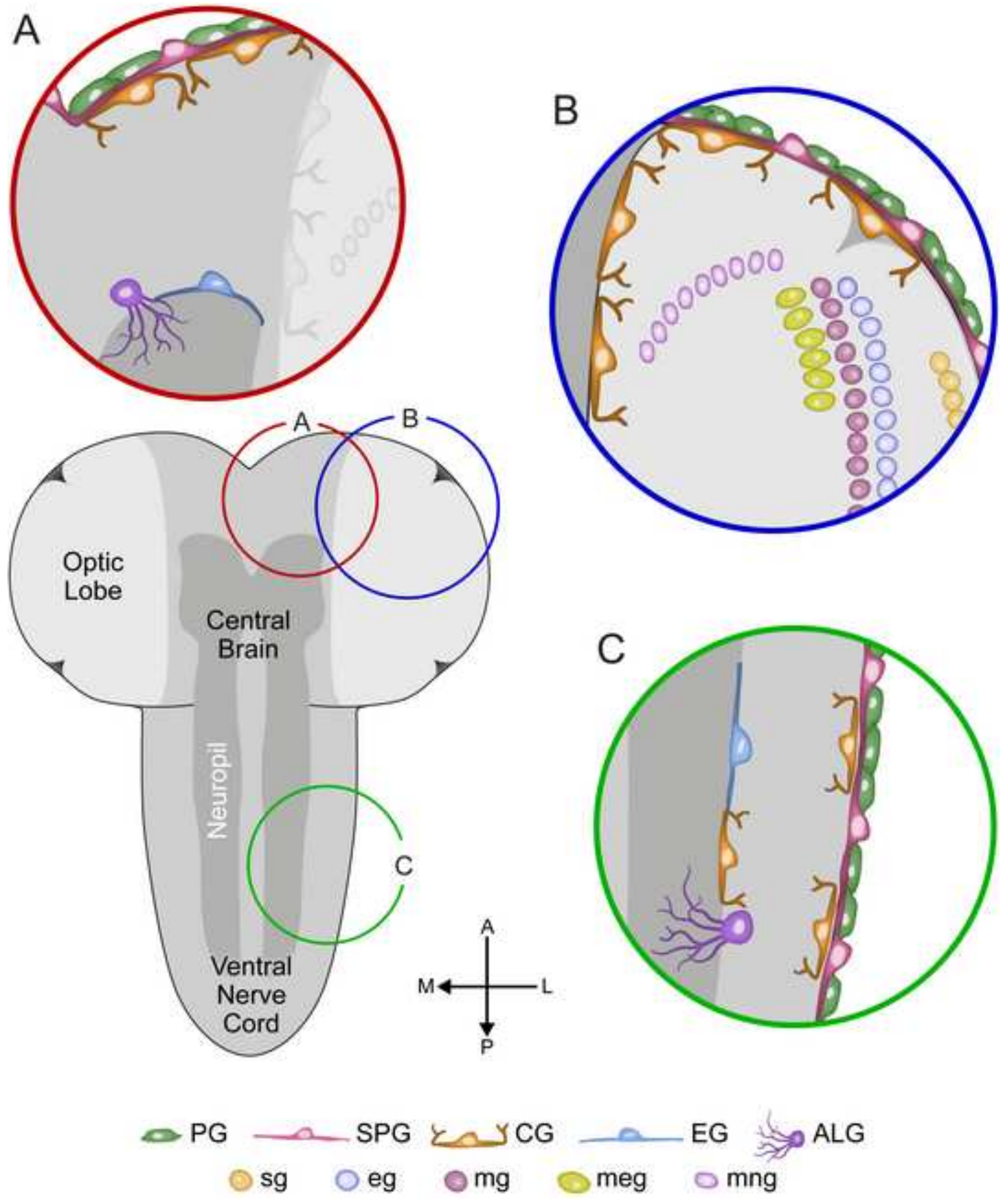

